\title{
Julio Cortázar: el jazz y América.
}

\section{Julio Cortázar: Jazz and America.}

\section{Resumen}

El corpus literario de Julio Cortázar se explica partiendo del origen de su narrativa en un contexto cuya naturaleza es sincrética y está cimentada en dispares orígenes e influencias culturales que caracterizan al producto cultural americano. Es en la música y en la literatura donde para Cortázar los distintos lenguajes sirven de cauce por el que se canalizan las distintas influencias. Este carácter sincrético por el que se trasvasan lógicas otras heredadas de tradiciones otras posiciona al intelectual americano en la problemática de la identidad y, consecutivamente para Cortázar, en el compromiso.

Palabras claves América, poscolonialismo, sincretismo, Julio Cortázar, jazz.

\begin{abstract}
The Julio Cortazar`s literary corpus can be explained from the origin of his narrative in a context whose main feature it is the syncretic nature that it is grounded in the different origins and cultural influences that characterize the American cultural product. It is in music and literature where, to Cortazar, the different languages serve as a channel through which these influences of various kinds are transferred. This syncretic character by which others logical traditions are inherited from others, positions the american intellectual in the problem of identity, and in Cortazar case, in the field of commitment.
\end{abstract}

Keywords America, Postcolonialism, Syncretism, Julio Cortazar, Jazz.

Muchas veces se ha querido ver el gusto de Julio Cortázar por el jazz como una imagen poética más en vida de las que ya nos hubiera dejado en su escritura al cabo de estos cien años. A propósito de su muerte dice Jorge 
Boccanera que indisociablemente "la obra de un artista es también la conciencia de ese artista" (30-31). El hecho es a subrayar porque muchas veces se soslaya, se hace literatura, cuando no occidentalismo. Ocurre que se hace hincapié en el tema del jazz en Cortázar como un legado más adquirido o reivindicado por el escritor en París. Esa ciudad que le permitió la libertad que como ciudadano necesitaba inminente y constante para poder trabajar desde su posición de intelectual latinoamericano comprometido; pero París jamás deja de ser ese lado de allá que diferencia del otro lado, del lado de acá, y el jazz ya lo traía de herencia desde la Argentina, de la América: "El pueblo negro descargará un tremendo golpe de tambor que habrá de oírse de punta a punta en nuestras tierras; carentes de cultura literaria, aportarán la del ritmo y el color, que a su manera encontraran luego su camino en las estructuras literarias latinoamericanas" (Cortázar, Obra crítica 279).

La crítica siempre es otra cosa, una lectura acaso. Francia al final de su vida le otorga la nacionalidad que llevaba años solicitando y finalmente quiere dejar su huella en Cortázar europeizando en parte su figura: "Ya hay muchos que me han convertido en francés porque les conviene; [...] lo único que falta es que algún "crítico" escriba un día un ensayo mostrando que Rayuela es la novela de un francés traducida al español" (Cortázar, Clases 230-231). La crítica articula un discurso occidentalista a través de la idea de la influencia del surrealismo francés en su escritura, en su técnica y temas. En este sentido hay críticas debidamente matizadas como la de Alain Sicard, que le considera más bien un surrealista desencantado debido a la idea de desencuentro que desarrolla en su trabajo respecto a Cortázar:

Es un surrealista, pero un surrealista que ha perdido la fe en todo eso; un hombre que está a medio camino entre aquella utopía del surrealismo y lo que llamaría el territorio de la historia: la historia que es el campo de lo relativo, de lo insatisfactorio, del compromiso y las claudicaciones. Intentaba desesperadamente reunir la utopía y el territorio, lo que es una 
tarea muy complicada. Por eso me parece que es un intelectual muy ejemplar, de su siglo. Tal vez podamos decir que toda la historia del siglo XX es la historia de dos utopías, la gran utopía estética y la gran utopía política. (Sicard, Entrevista 33)

Las corrientes vanguardistas le son heredadas a Cortázar y a su generación por la vía europea y el canal del idioma, mientras que del otro lado, de su mismo norte, Estados Unidos, le llega el legado del jazz. También esta música poseedora de tradiciones coetáneas a él, e, igualmente, de gran ruptura epistemológica respecto a la tradición. El jazz supone una ruptura epistemológica respecto a la tradición propia africana y a la de la música occidental anterior. Frente a ella significa quiebra del sistema y cambios de paradigma, por lo que igualmente tiene, como en su campo el surrealismo o el existencialismo, un lugar cardinal en los cambios históricos de concepción teórica sobre el arte y lo concerniente a la creación.

La cultura define los límites de la identidad, siendo ambos términos, cultura e identidad, simbióticos en la antropología del arte. En nuestro mundo globalizado, cada vez se acentúa más la existencia de una cultura dominante hegemónica o central, y otras periféricas desde donde se articulan las críticas a la modernidad respecto a sus cimientos colonizadores y genocidas. La otredad como discurso desde un lugar de enunciación distinto del dominante es silenciada o asimilada por el discurso occidentalista, que, si la asimila, la reconfigura en sus propios sentidos y significados, mostrando un nuevo proceso de colonización de la cultura. Por eso, autores como Mignolo entienden que el occidentalismo adhiere la diferencia, siendo únicamente posible la crítica a la modernidad desde el posoccidentalismo (2007). Otros críticos como Richard indican que hay una brecha entre la representación y la autonomía de la realidad (1998), lo que patenta la desigualdad entre los sujetos representados y los que patentan los códigos de esa representación. 
El corpus literario de Julio Cortázar se explica partiendo de Argentina como origen y cuyo contexto americano es de naturaleza sincrética en cuanto cimentada en dispares orígenes e influencias culturales que caracterizan al producto cultural americano. El sincretismo cultural ocurre porque los significados no son entidades estáticas. Ocurre en espacios de coexistencia social donde un grupo oprime al resto, quienes dejan sus múltiples sustratos culturales en estéticas híbridas que abandonan los espacios límite de las tradiciones ortodoxas ampliando su paradigma. Es en la música y en la literatura donde, para Cortázar, los distintos lenguajes sirven de cauce por el que se canalizan las distintas influencias. Este carácter sincrético por el que se trasvasan lógicas otras, heredadas de tradiciones otras, posiciona al intelectual americano en la problemática de la identidad y, consecutivamente para Cortázar y los músicos de jazz, en el compromiso y reclamo de sus propias formas y tradiciones. Vienen a reivindicar su propia memoria sobre la que el occidentalismo ha reescrito su historia, despojando a las distintas estéticas de sus éticas intrínsecas y recomponiéndolas alrededor de la razón heredera de la ilustración. Cortázar reconoce precisamente un desplazamiento de la formas racionales a partir de poetas que, en línea con Bergson (1896) y sus ideas del relativismo de la duración temporal, aluden a otra subjetividad como principio regidor. Cortázar se forma como escritor en el simbolismo francés y sus correspondencias, pero rápido su generación conoce a Neruda, que les devuelve a lo americano y que invita a seguir a estos nuevos poetas, con Vallejo o Lezama Lima, fuera del tiempo europeo y en sus propias categorías, que no responden a la lógica occidentalista de la realidad. Cortázar bebe de la tradición francesa en sus distintas vertientes, rescatando el elemento musical y la intuición como vía otra de conocimiento al que aludían autores como Verlaine, Baudelaire o el citado Bergson, pero es Neruda el que viene a cubrir la necesidad de un lenguaje común en la región americana. En este sentido, Cortázar llama a la Latinoamerica-no-oficial a reconocer su existencia en sus propios discursos y en sus propios estilos, que aún cuando parecen herméticos o elitistas, por lo complicado a nivel técnico de sus 
formas, está buscándose sin infravalorar la capacidad intelectual de la región como se venía haciendo con el silenciamiento teórico.

Ya el surrealismo y el existencialismo sacan a Cortázar del racionalismo, pero es el jazz el que le abre el campo a nuevas posibilidades con las variaciones musicales. Gracias a ellas sale en busca de lo inaudito tomando de la tradición del jazz de EE.UU. las formas de acción y no solo una búsqueda que se quede en lo formal. García Márquez recuerda cómo Carlos Fuentes pregunta a Cortázar en un viaje por la introducción del piano en la orquesta de jazz y que tras eso, "Cortázar, que sabía medir muy bien sus palabras, nos hizo una recomposición histórica y estética [...] que culminó con las primeras luces en una apología homérica de Thelonious Monk" (Álvarez Garriga, Clases 13). Como la pintura abstracta viene a liberar de lo figurativo, así la lógica otra del jazz y de Cortázar liberan de lo convencional: "Sí, a veces la puerta ha empezado a abrirse [...] Toda mi vida he buscado en mi música que esa puerta se abriera al fin... porque no puede ser que no haya otra cosa, no puede ser que estemos tan cerca, tan del otro lado de la puerta..." (Cortázar, Las armas 34).

El sincretismo queda en las formas como sustrato de tradición oral donde el conocimiento se transmite con menos mediación al no estar enfocado desde lo escrito. El jazz busca una libertad de expresión que no se entiende sin ese sustrato oral de la tradición africana. Además, esa libertad se busca desde un sentimiento identitario que se sabe diferente. La oralidad representa una voz concreta, otra. Cortázar no trata de representar o imitar la realidad y recrearla, busca transformarla por su escritura; y su reestructuración no la entiende de otro modo que por medio del lector, al que comunicará su pulso e intención por medio del oído interno que supone la lectura en cualquier caso. La obra es una vía de comunicación con el otro para crear juntos una realidad sin trucos ni máscaras:

[...] la poesía sigue siendo la mejor posibilidad humana de operar un encuentro [...] y que puede hacer del hombre el laboratorio central de 
donde alguna vez saldrá lo definitivamente humano, a menos que antes no nos hayamos ido todos al quinto carajo. (Cortázar, Último round 54)

Busca en la literatura, no un servilismo a la razón y a sus fines utilitaristas, sino el cuestionamiento al pensamiento occidental. Sus personajes a menudo son seres desterrados y extrañados en una realidad que funciona sobre otras categorías que les son ajenas. Fuentes constata que se dio cuenta del latinoamericanismo de Cortázar en Buenos Aires: "Novela latinoamericana, Rayuela lo es porque participa de una atmósfera mágica de peregrinación inconclusa” (Fuentes, La nueva novela 68). En este sentido comparte con la diáspora africana una transposición de lugar geográfico que reconfigura la identidad de la cultura y de los elementos que la conforman, como son la ética y la estética, bajo nuevos escenarios históricos. Trata la realidad como múltiple, compuesta de los opuestos que en simultaneidad se anulan como tales y presentan la utopía. Lo monstruoso es lo revolucionario, es el ansiado salto a lo otro, a lo distinto.

La música es siempre intrínseca a lo poético aunque la crítica siempre lea a Mallarmé o a Rimbaud en primera instancia en Cortázar a pesar de contar con referentes musicales populares tan directos como el jazz:

En sus conferencias en Berkeley de 1984, Cortázar habló de esa condición de música que la prosa alcanza en sus mejores momentos. No hablaba de los efectos musicales de la prosa o la poesía simbolistas, sino de una cierta estructura sintáctica, de una cierta cadencia que, sin imitar la música, procede como ella, organizando frases y palabras en una arquitectura encantatoria. Esa alta conciencia del oficio lo acompañará desde sus inicios de escritor hasta sus textos más tardíos. (Alazraki, Hacia Cortázar 28)

Cortázar en exilio es lo argentino en Europa que jamás dejará de escribir en el idioma que le impusieron históricamente pero que ya ha hecho suyo para 
finalmente trasladarse de su contexto en diáspora y tomar esta lengua ya como propia herramienta diferenciadora:

Como tantos latinoamericanos que escribieron y escriben en español a miles de kilómetros de sus patrias, mantengo el contacto con mis hermanos prisioneros o vilipendiados, escribo para ellos porque escribo en su idioma que siempre será el mío, busco junto con tantos otros la manera de llevarles aliento y contribuir a su liberación. (Cortázar, Obra crítica 174)

En Cortázar se enraízan las distintas tradiciones que, asimiladas y hechas propias, son ya desde una conciencia de lo foráneo y lo propio plenamente clara; lo que conlleva en sí una respuesta a la ortodoxia del canon occidental, como el jazz supone en sí mismo y como dentro de su clasificación supone el bebop; en Último round Cortázar nos dice:

A lo mejor a usted le sirve de consuelo enterarse concretamente de que los argentinos o los bolivianos no somos los únicos (con otros veinte o treinta países y paisitos del tercer mundo) que padecemos la injerencia norteamericana en nuestra así llamada soberanía. (104)

El acercamiento al jazz ocurre en Cortázar desde el tratamiento del lenguaje. La lengua es la realidad inmediata del escritor y es desde donde emprende su revolución una vez que considera caídas las máscaras de la globalización que quería una Latinoamérica sumida en el inmovilismo. Lejos de ello, la literatura latinoamericana se vuelve inclasificable y, esa indeterminación en el desorden de los géneros funciona como un paradigma que excede los límites de la tradición occidental. En este sentido, Cortázar alude a la que considera su lengua para distanciarse de lo europeo metropolitano que significó la lengua francesa: 
Escribo y escribiré toda mi vida en español: el francés lo guardo para la correspondencia cuando tengo que escribirle a algún francés. El español es mi lengua de escritor y hoy más que nunca creo que la defensa del español como lengua forma parte de una larga lucha en América Latina que abarca muchos otros temas y muchas otras razones de lucha. [...] mi lengua es el español y lo será siempre. (Clases 105)

Cortázar no es francés ni europeo, ni lo que tiene de francés o europeo es otra cosa que no sea ya americana porque, a pesar de pasar treinta y dos años en Francia, siempre escribirá en español hasta su muerte (Cortázar, 1983). Siempre sería un argentino en París, en Francia o en Europa. Su manera de sentipensar, su atmósfera y su mood no será sino su conciencia argentina de exiliado americano:

Gabriel se había hecho reembolsar el pasaje de regreso para quedarse en París, vendiendo los periódicos atrasados y las botellas vacías que las camareras sacaban de un hotel lúgubre de la calle Dauphine. Aureliano podía imaginarlo entonces con un suéter de cuello alto que sólo se quitaba cuando las terrazas de Montparnasse se llenaban de enamorados primaverales, y durmiendo de día y escribiendo de noche para confundir el hambre, en el cuarto oloroso a espuma de coliflores hervidos donde había de morir Rocamadour. (Rayuela 422-423)

La literatura agita conciencias como así la música, que no le llega a Cortázar tanto del lado de la literatura sino de la música misma. El jazz como resultado de la diáspora africana en EE.UU., mezclada con lo indígena americano y el dominador europeo de ambos, llega a Cortázar por radio en su infancia para no abandonarlo nunca y comprometerle con la historia, las identidades de las culturas y la libertad. El jazz no es tanto escritura automática sino lenguaje oral improvisado. Es una poética de lo oral y, además, el jazz funciona por la diáspora 
como una broterhood frente a fronteras. Cortázar entiende que el jazz acerca a la humanidad por ser una música sin nación al ser hija de la diáspora. Por eso se reconocen sus hijos en todas partes: el jazz funciona como una seña de identidad, como una nacionalidad.

La tradición oral africana se patenta como sustrato en la tradición musical afroamericana con elementos claros como las variaciones. La función distintiva del ritmo y tono pervive a pesar de que las lenguas tonales africanas se olviden en el nuevo territorio; se olvidan con las generaciones pero dejan igualmente su huella en el sustrato musical con el tratamiento del ritmo y el swing como marca distintiva y rasgo diferenciador desde una respiración concreta, una forma de enunciar. La música funciona como trasmisor cultural en las canciones de llamada y respuesta, pero además como lugar común en el que confluye el margen en su lenguaje doble y propio. Escribir entre líneas con el idioma del dominador porque la inclinación de Cortázar al jazz no responde a una estética ornamental, sino a una ética que comparte de sus mismos sustratos. Esta es la crítica de Cortázar a la razón pragmático-cartesiana que entiende una única forma de realidad. Cortázar transporta las formas del jazz a su escritura y así la conciencia del lector despierta a una memoria intuitiva por medio del ritmo que transporta por analogía el mensaje desde el nivel formal de su código. El ritmo encandila al lector para apresarlo por el efecto del canto, lo que resulta en un estado otro de conciencia. El jazz es una búsqueda, un método de exploración vivo. Es un lugar donde la realidad es porosa y trasmutable la identidad y la alteridad por los efectos auditivos. El sonido importa a nivel pragmático por cuanto comunica el ritmo:

[...] mi ritmo de escritura se basa en frases habitualmente extensas, en las que las comas están a la manera de los puntos, lo cual a veces es incorrecto pero me permite lograr una especie de swing en mi escritura, una respiración que le da, creo, su sentido. (Cortázar, Clases 515- 516) 
Las intersecciones de las variaciones transmiten sentido ontológico y existencial. La utopía es inalcanzable por cuanto el muro de la razón esté conteniendo y bloqueando las posibilidades del lenguaje. Para Cortázar, el jazz es un camino a la utopía del encuentro con el otro y así poder lograr el entendimiento mutuo. Es utilizado como método para salirse del tiempo y estar todos en comunicación atemporal. Así, en Rayuela, la forma es el fondo como un todo donde propone la fragmentación como una posibilidad que confiere de sentido. El jazz en Rayuela es tema, trama y método. La improvisación será la reinterpretación inventiva que rompe con lo establecido para dar nuevos sentidos.

La historia de la industria musical en EE.UU. es paralela a la historia del jazz, donde confluye en sincretismo la diáspora negra, los indígenas llamados a ser exterminados y la armonía musical de la tradición occidental europea judía. La modernidad se abre paso en la historia con estos tres genocidios. Por eso en el seno de esta música es donde nace el sentimiento de diferencia con el bebop, que llega para reivindicar el espacio del negro que inmediatamente la cultura blanca pretende aglutinar como su tradición, como su propio folclore, silenciando su origen al tomarlo como manifestación popular, olvidando los sujetos de su producción que fueron enfrentados en las guerras por la independencia, y convertirlo así al fin en parte de la industria al ver en él personalizado este sincretismo que la industria tratará de envolver con el márketing de la globalización para comerciar con la diferencia y así asimilarla en su mercado democratizador. El swing fue el estilo asimilado por la cultura occidental de estas formas y su difusión por radio fue ya utilizado como un márketing de masas por la democracia. El bebop como estilo es una respuesta a ese apropiamiento desde una conciencia a nivel técnico, estético, y ético. El bebop es en sí una revolución multinivel. Este proceso es paralelo a la revolución negra por los derechos civiles y paralelo a la vez al sentimiento revolucionario en la historia de Latinoamérica.

Cortázar y el bebop comparten un relativismo temporal y una simultaneidad de la emoción frente a lo material; pero sobre todo, ambos comparten la sospecha de un orden más allá del racional y el tangible, que por no 
responder a ello nos parece caos. En Cortázar todo esto confluye en una intención de decir por otras vertientes, más allá de la razón pragmática, no ya en la mente. Una forma de decir que responde a una sensibilidad o inteligencia otra que alcanza comunicar por medio del ritmo con swing. En la escritura de Cortázar, la razón se organiza en función de parámetros que en la tradición occidental estuvieron lejos del concepto de racionalidad. El humor, el juego o la misma locura siempre están en un más allá de lo inmediato, en otra parte. Lo lúdico en concreto entra a formar parte de la obra de Cortázar por la vía de lo fantástico y de la trasposición de la realidad. Son tratados como modos para salir de la cotidianeidad. Jugar para Cortázar es entender desde otra perspectiva y llega a implicar en el mismo juego al lector, al otro -tan múltiple como posible-, quien ha de pactar las reglas que por lo demás son laxas a niveles formales.

Pero hay un sentido más imbricado al corpus de Cortázar en el tratamiento y los usos del juego, la locura, el jazz y, en resumen, todo orden otro que no responde al canon inmediato. La lectura, el juego o la música conectan las formas empáticas por medio de la otredad y la alteridad, la identificación o la trasposición, y así comunican sus valores. Para Cortázar, este ludos no trata sino de sacar al lector del paradigma occidental enturbiando sus reglas para sumergirlo en lugares distintos donde finalmente el mismo juego se vuelve un tema de seriedad implicando a ese mismo otro y a ese lector que viene a reunir en el compromiso histórico cuando la realidad o el otro lado del espejo significa exilio, diáspora y sincretismo de esas formas culturales oprimidas, silenciadas y expoliadas:

[...] leer o escribir literatura supone la presencia irrenunciable del contexto histórico y geopolítico dentro del cual se cumplen esa lectura o esa escritura; supone la trágica diáspora de una parte más que importante de sus productores y de sus consumidores; supone el exilio como condicionante forzoso de casi toda la producción significativa de los intelectuales, artistas y científicos de Chile, Argentina y Uruguay entre 
otros muchos países. Vivimos la paradoja cotidiana de que una parte no desdeñable de nuestra literatura nace hoy en Estocolmo, en Milán, en Berlín, en Nueva York, y que dentro de América Latina los países de asilo como México o Venezuela ven aparecer casi diariamente en sus propias editoriales muchas obras que en distintas circunstancias les hubieran llegado de Buenos Aires, de Santiago o de Asunción. [...] factores [...] presentes en la memoria y en la conciencia de cualquier escritor que trate de ver claro en su oficio; de todas estas cosas es necesario hablar, porque sólo así estaremos hablando verdaderamente de nuestra realidad y de nuestra literatura. (Clases 295) ${ }^{1}$

El cuento como género tiene una raíz oral indiscutible además de poder transformar las leyes naturales y el mundo respondiendo a su propia lógica, quebrando los límites en su proximidad a lo poético que procede por medio de la analogía del lenguaje. Esta vía fantástica del cuento no está enfrentada al realismo en primera instancia, sino que ofrece la posibilidad de conectar con la historia y la realidad de los otros. El orden otro de las cosas se explora por las excepciones a las leyes naturales que quiebran la lógica de la realidad haciendo emerger el pensamiento intuitivo. Lo fantástico en Cortázar es la alteridad y la realidad otra a la que se llega por medio del lenguaje que delata otras realidades por medio de los elementos de intensidad y tensión que se trasmiten al otro. Hay un extrañamiento del lenguaje que ha de ser guiado por la intuición para lograr comunicar otros mundos. La escritura de Cortázar desplaza la realidad conocida por medio del humor, la locura o el juego, elementos también presentes en el jazz. Son los caminos a la descolonización de la razón por ser mecanismos subversivos a las lógicas hegemónicas. Son nuevos enfoques para entrever la realidad. Jugar con el lenguaje es para Cortázar tantear los límites, la palabra es creadora cuando busca alternativa abierta. Esta forma, comunicada al lector, trasmite a su conciencia el

\footnotetext{
${ }^{1}$ En la versión inglesa Garriga dice que añade: “and I know all too well that these factors are frequently neglected in academic research and literary criticism".
} 
encuentro, que será la razón de la escritura de Cortázar. La insuficiencia del lenguaje será salvada por lo poético que logra desatar lo fantástico. Partirá desde lo poético que aborda desde la inteligencia de la analogía y la intuición frente a la cartesiana, más cercana a la música que a la gramática. La poesía comunica por su musicalidad. Por eso Cortázar aboga por rescatar este lenguaje frente al enunciativo-estético, para liberar los sentidos que constriñen las palabras a la hora de enunciar otras realidades. Solo así se logra sacar al lector de la realidad falseada. Como ocurre con Poe -que también bebe en su infancia de la tradición afroamericana-, a partir de un elemento formal auditivo, el lector-oyente es secuestrado a una realidad que responde a otro orden. La analogía es el sistema de variaciones sobre el tema, supone una lectura otra, le permite la trasmutación de las identidades por participación, es la otredad por medio de las variaciones que desdoblan la realidad.

La ausencia de partitura en el jazz no debe ser tomado como desorden, es una lógica secuencial propia que responde al componente de libertad. Es la conciencia panamericana la que hace que Cortázar recoja la tradición del jazz. Rayuela y "El perseguidor" son el camino de la verdadera implicación de Cortázar con la humanidad y los problemas existenciales y de falta de libertad que nos unen a todos y que se encuentran en estrecha relación con los problemas técnicos musicales del jazz a la hora de improvisar o interpretar y respecto a la medición del tiempo. La realidad no es aprehensible unilateralmente y es esta la idea que se encuentra ligada a la noción de alteridad. Por eso Bruno, en "El perseguidor", encarna la crítica a la crítica que evita el salto a lo otro y al otro. En este sentido, el sincretismo juega un papel importante en la contra-hegemonía. Por el lenguaje se canalizan las lógicas otras que posicionan al artista en las problemáticas de la identidad y la libertad. El lenguaje oral es también conquistado por la letra, pero deja un sustrato de libertad por su naturaleza oral que se rastrea en el jazz como en Cortázar, y que viene a recoger una tradición también viva en Latinoamérica por la vía de la cuentística y las reconfiguraciones de las mitologías occidentales desde la evangelización. Cortázar introduce una intención revolucionaria en sus 
textos partiendo de la reconquista del lenguaje como implicado en la realidad histórica. Para Cortázar, su compromiso es paulatinamente cada vez más con la humanidad y contra la represión sistematizada en Latinoamérica. Una vez implicado con esto, siente la necesidad de comunicarlo. El exilio, la censura y la muerte han de ser respondidos para no separar Latinoamérica de su producción y pensamiento. Es esta la conciencia en Cortázar que atraviesa toda su obra de modo exponencial.

\section{Bibliografía}

Alazraki, Jaime. Hacia Cortázar: aproximaciones a su obra. Barcelona: Anthropos, 1994. Impreso.

Álvarez Garriga, Carles. Julio Cortázar. Clases de literatura. Berkeley, 1980. Madrid: Alfaguara, 2013. Impreso.

Bergson, Henri. "Materia y memoria". 1896. Obras escogidas. Trad. José Antonio Miguez. Madrid: Aguilar, 1963. Impreso.

Boccanera, Jorge, "Julio Cortázar, el sueño y la vigilia". Documento 106 de la carpeta 68 del Fondo Julio Cortázar. Universidad de Poitiers: Centre de Recherches Latinoamericaines, 1984. Impreso.

Cortázar, Julio. Las armas secretas. Buenos Aires: Editorial sudamericana, 1959. Impreso. . Último round, II. México: Siglo XXI, 1969. Impreso. . Julio Cortázar. El último adiós. Buenos Aires: Producciones sudestada, 1983. Audio: CD.

. Rayuela. Buenos Aires: Editorial Sudamericana, 1963. Impreso.

Fuentes, Carlos, La nueva novela hispanoamericana. México: Joaquín Mortin, 1969. Impreso.

Mignolo, Walter. "La razón poscolonial: herencias coloniales y teorías poscoloniales". En: de Toro, Alfonso. (ed.) Posmodernidad y poscolonialidad. breves reflexiones sobre Latinoamérica. Frankfurt: Vervuert, 2007.

Sicard, Alain. "Entrevista a Alain Sicard". Entr. Susana Gómez. Gómez, Susana. Fondo Cortázar en Poitiers (y otras cercanías). Poitiers: CRLA- Archivos, 2008. Impreso.

Sosnowski, Saúl. Julio Cortázar. Obra crítica/3. Madrid: Alfaguara, 1994. Impreso.

Richard, Nelly, "Intersectando Latinoamérica con el Latinoamericanismo: discurso académico y crítica cultural". En: Castro-gómez, Santiago y 
CATEDRAL TOMADA: Revista literaria latinoamericana / Journal of Latin American Literary Criticism Araceli Abras Daneri

Mendieta, Eduardo. Teorías sin disciplina (latinoamericanismo, poscolonialidad y globalización en debate). Edición de Miguel Ángel Porrúa. México, 1998. Impreso. 